\section{SURGERY OF THE SHOULDER}

By Anthony F. DePalma, M.D. Pp. xix +438 , with 454 illustrations. London and Philadelphia : J. B. Lippincott Co. 1950. £7.

This is a monograph on the surgery of the shoulder. It is a major work containing the pith of recent advances in the anatomy, physiology, pathology and treatment of the various conditions affecting this group of joints and their surrounding structures.

A chapter on the anatomical variations and degenerative lesions is original work and is a valuable addition to the knowledge of this difficult region. The controversial topics of "frozen shoulder,' bicipital tenosynovitis, injuries and degenerations of the musculo-tendinous cuff, recurrent dislocation and the multiple causes of shoulder pain arising in the cervical spine and base of the neck, are dealt with in a masterly way.

This book is full of information which is clearly set out and documented and contains at the end of each chapter ample references. Generally the illustrations reach a high standard, the sketches by Brill are well drawn, simple and explicit, and the photography of the specimens showing anatomical variations is excellent.

There is little to criticize in this book and no doubt it will take its place as a guide in the practice of surgery and as a reference volume for practitioners of medicine as a whole.

\section{P.H.N.}

\section{PHYSICS IN MEDICAL RADIOLOGY}

By Sidney Russ, C.B.E., D.Sc., F.Inst.P., L. H. Clark, Ph.D., F.Inst.P., and S. R. Pelc, D.Ph. and Edition (revised). Pp. viii +296 , with 106 illustrations. London: Chapman and Hall. I $950.25 \mathrm{~s}$.

The first edition of this book was written in 1928 , and has been completely revised and rewritten in order to bring it up to date with modern developments. It covers fairly completely the physics requirements for the D.M.R. examinations, and includes far better accounts on electrostatics, current electricity and electrotechnics than is found in other books of this type. The sections on X-rays and radioactivity are admirably lucid, and there is a good new chapter on photography. One might wish, however, for an additional chapter or two on some more recent activities in the sphere of atomic physics.

The book as a whole is strongly to be recommended to those associated with medical radiology, and may be glanced through with interest by those interested in this wider aspect of medicine.

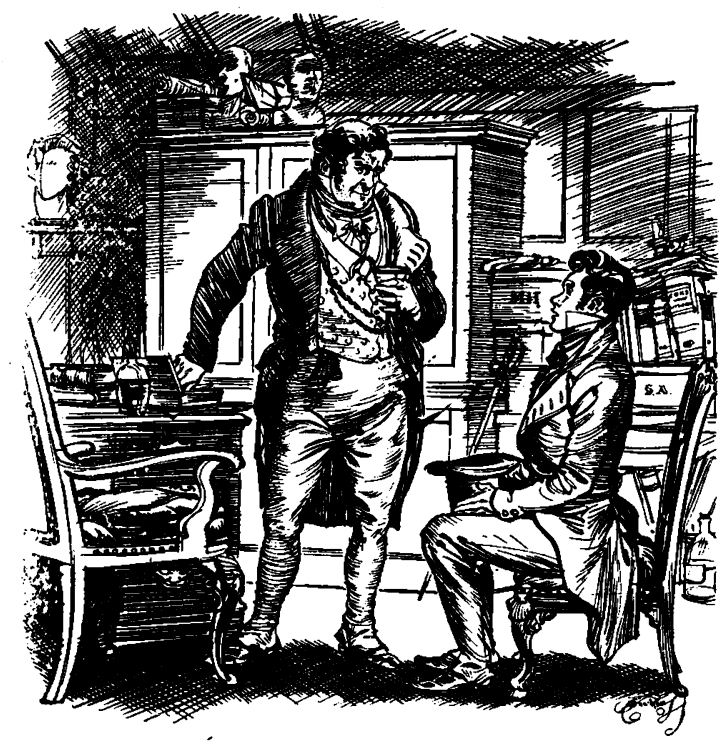

\section{Pip receives his Allowance}

"My guardian then took me into his own room, and while he lunched standing ... informed me what arrangements he had made for me... Also, I was told what my allowance was to be..." 'GREAT EXPECTATIONS' by Charles Dickens

Men like Mr. Jaggers are rare today, and mysterious benefactors rarer still, but should one of them undertake the education of a young man, he might well follow the example of the many wise fathers who introduce their sons to the Midland Bank and pay their allowances through the Bink's “Standing Order" service. This facility, available to all the Bank's customers, relieves them of the responsibility of remembering the dates for payment of rent, rates, allowances, school fees, insurance premiums and the like. The Bank will do their remembering for them.

MIDLAND BANK LIMITED 